\title{
Generic Skills Assessment Through Implementation of Group Based Learning to Understand SDGs
}

\author{
Namita Maharjan \\ Graduate School of Engineering, Nagaoka University of Technology \\ PO box 940-2137 Kamitomiokamachi 1603-1, Nagaoka, Niigata, Japan \\ Tel: 0258-47-9923 E-mail: namita.maharjan@yahoo.com \\ Kyohei Kuroda \\ Miyakonojo College, National Institute of Technology \\ PO box 885-8567 Yoshio-cho 473-1, Miyakonojo, Miyazaki, Japan \\ Tel : 0986-47-1227 E-mail: kkuroda@cc.miyakonojo-nct.ac.jp \\ Misuzu Okada \\ Ube College, National Institute of Technology \\ PO box 755-0097 Tokiwadai 2-14-1, Ube, Yamaguchi \\ Tel: 0836-31-6111 Email: okadam@ube-k.ac.jp \\ Shigeyoshi Nakamura \\ Ube College, National Institute of Technology \\ PO box 755-0097 Tokiwadai 2-14-1, Ube, Yamaguchi \\ Tel: 0836-35-8029 Email: snakamura@ube-k.ac.jp \\ Hideaki Aburatani \\ Kitakyushu College, National Institute of Technology \\ PO box 802-0985 Kokuraminami 205, Kitakyushu, Fukuoka \\ Tel: 093-964-7200 Email: abura@kct.ac.jp \\ Takashi Yamaguchi \\ Graduate School of Engineering, Nagaoka University of Technology \\ PO box 940-2137 Kamitomiokamachi 1603-1, Nagaoka, Niigata, Japan \\ Tel: 0258-47-9612 E-mail: ecoya@vos.nagaokaut.ac.jp \\ Makoto Ichitsubo \\ Graduate School of Engineering, Nagaoka University of Technology \\ PO box 940-2137 Kamitomiokamachi 1603-1, Nagaoka, Niigata, Japan \\ Tel: 0258-47-9811 E-mail: ichitubo@vos.nagaokaut.ac.jp
}

\begin{abstract}
In this competitive world, it is important for students to acquire generic skills and its assessment in higher education is scarce. This study is an attempt to address the effect of group based learning on generic skills development and and also an approach to spread the knowledge of Sustainable Development Goals (SDGs). Like generic skills, educating young students about SDGs has become crucial. A workshop was conducted for 3 days and a total of 12 students filled in the questionnaire for group and self assessment of generic skills for 10 selected generic skills after every workshop. The overall results indicated that the group based learning have positive impact on the development of generic skills. We found that all generic skills were more developed in group assessment than individual assessment. When the inter-relationship among the skills were assessed for individual ratings using network analysis, the results revealed that the effective team work was strongly associated with co-operativity $\left(\mathrm{r}^{2}=0.7529 \mathrm{p}<0.001\right)$, communication $\left(\mathrm{r}^{2}=0.7146, \mathrm{p}<0.001\right)$ and information sharing $\left(\mathrm{r}^{2}=0.7529 \mathrm{p}<0.001\right)$. The significant finding of this study is the use of shared educational materials which helped the students to overcome the language barrier and be more interactive to achieve the given goal. Further, this study has explored the application of group based learning as an effective educational approach to introduce any designed studies (in this case, SDGs) for fostering the innovative human resources belonging to different educational backgrounds. Moreover, this study also emphasizes on the importance of teaching SDGs to the engineering students for their capacity building, so that they not only understand but also act to ensure that the goals are met for better future.

Keywords: Engineering students, Generic skills, Group based learning, Self assessment, Group Assessment Sustainable Development Goals (SDGs).
\end{abstract}




\section{DOI: $10.7176 / \mathrm{JEP} / 10-6-03$}

\section{Introduction}

The dynamic world of globalization, science and technology innovations is demanding more versatile and adaptable manpower. To confront challenges imposed by these profound changes graduates now require a far broader range of non technical core competencies than the technical capabilities that was demanded in earlier days (Nguyen, 1998). These competencies can also be referred to as Generic skills. Generic skills include basic or enabling skills to complex reasoning skills which defines the competency of an individual to perform a task (Stasz et al., 1990). According to Assessment and Teaching of $21^{\text {st }}$ century skills (AT21CS, 2010) project, generic skills are those skills which address ways of thinking (i.e. critical thinking, problem solving creativity), ways of working (i.e. communication and collaboration), tools for working (i.e. information and communication technology literacy) and ways of living in this world (i.e. personal and social responsibilities). These core competences are fostered not primarily by teaching to deliver knowledge, but through teaching to stimulate specific kinds of cognitive activities (Glaser R. 1991).

In order to develop generic and employability skills for producing innovative human resources, different approaches of teachings and assessments have been extensively investigated (Kechagias et al., 2011). Particularly in Japan, universities are increasingly implementing changes by introducing more student-centered learning environments such as Active learning (Ito et al., 2017). As one of the most commonly used instructional methods of active learning, group or team based learning prepares the students to practice their course concepts to solve problems they are likely to face in the future (Gleason et al., 2011). This student-centered pedagogy is useful to all engineering students being highly related with their transition to university or for job hunting in diverse environment or to become efficient and productive individuals (Ichitsubo et al., 2016). Through active participation in a group work, any individual can explore his/her best qualities or generic skills while working in a diverse environment. Besides having other several benefits, under the watchful eyes of the facilitators, the students gradually learn to enhance their competencies while practicing with the content ( Lochman et al., 2010).

To conduct the group based learning we chose to introduce sustainable development goals (SDGs) to the students. SDGs are a set of 17 core objectives constituted by the United Nations and to be completed by 2030 with the spirit of partnership and pragmatism to improve life while making the right choice for the future generations. Education on SDGs should be the core of teaching and learning and should not be considered as an add-on to the existing curriculum (UNESCO, 2017). In this regard, as an attempt to familiarize students with the SDGs and engage them with sustainability-related issues as described in the SDGs, Nagaoka University of Technology (NUT) conducted an intensive workshop for a limited number of students. Our study is aimed at evaluating how a group work based learning supplementation effected the students`generic skills development in such a short span of time. Further this study examines the cumulative influence of group based learning on particular generic skills, using the self and group assessments as the measuring levels . Finally, the study provides new information on the varying generic skills profiles associated with self and group assessments during SDGs study.

\section{Materials and Methodology}

\subsection{Use of Large Sized Handouts (LSH)}

The activity included the introduction of SDGs to the students along with the keywords related to each specific goals by using Large sized Handouts (LSH) conceptualized by Aburatani (2016). LSH is a template for active learning which provides a common platform to share the ideas visually. It was first devised to help the teachers to enhance their facilitation skills, control over students and time management during problem-based learning and group based learning. The advantage of using this tool is that it can be freely designed according to the need of the subject matter.

\subsection{Set up of group work based learning}

This study was conducted by the intensive workshop organized by Nagaoka University of Technology, Nagaoka, Japan in Miyakonojo National College of Technology, Kagoshima, Japan. The topic of the workshop was to design a game for elementary students for teaching SDGs. For this study, a small size of 10 National Institute of Technology students including 2 international students were taken. The design of this workshop was based on the group based learning strategies described by Ichitsubo et al. (2016) in Figure 1. 


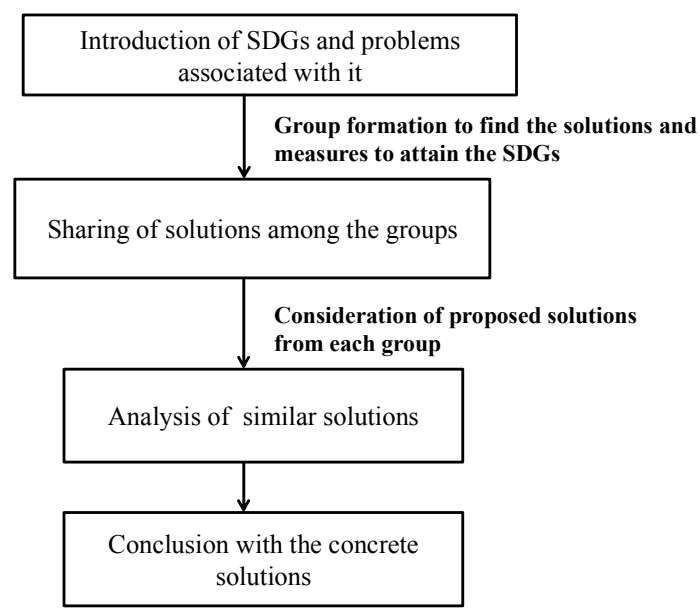

Figure 1. Flow of the workshop of group work-based learning (Ichitsubo et al., 2016)

The workshop was conducted for three days with the schedule as shown in Figure 2 by swapping the students among the groups everyday. On day 1 , the students were given time to introduce themselves by playing ice break games. The concept of SDGs was introduced by using SDGs cards with logo on the front and the keywords that aptly describe the goals at the back as shown in Figure 3. Each student was given 5 cards and time to memorize the keywords associated with the goals. Thereafter, they exchanged the cards and cross questioned each other to test their understanding of SDGs through keywords.

On day 2, the students were divided into three groups and were assigned the task of developing a friendly game to learn SDGs for elementary school students through group discussion by using instructions in the LSH. LSH was prepared as shown in Figure 4 with goal to "Design a game i.e carrom game to learn SDGs" and also directions to facilitate the students to set - up the games, how to play and its rules using Plus Minus Analysis. Finally, on day 3, the students designed the prototype and demonstrated its rules by presentation in English. Out of the presented designs, the best game design was decided by audience with the highest scores.

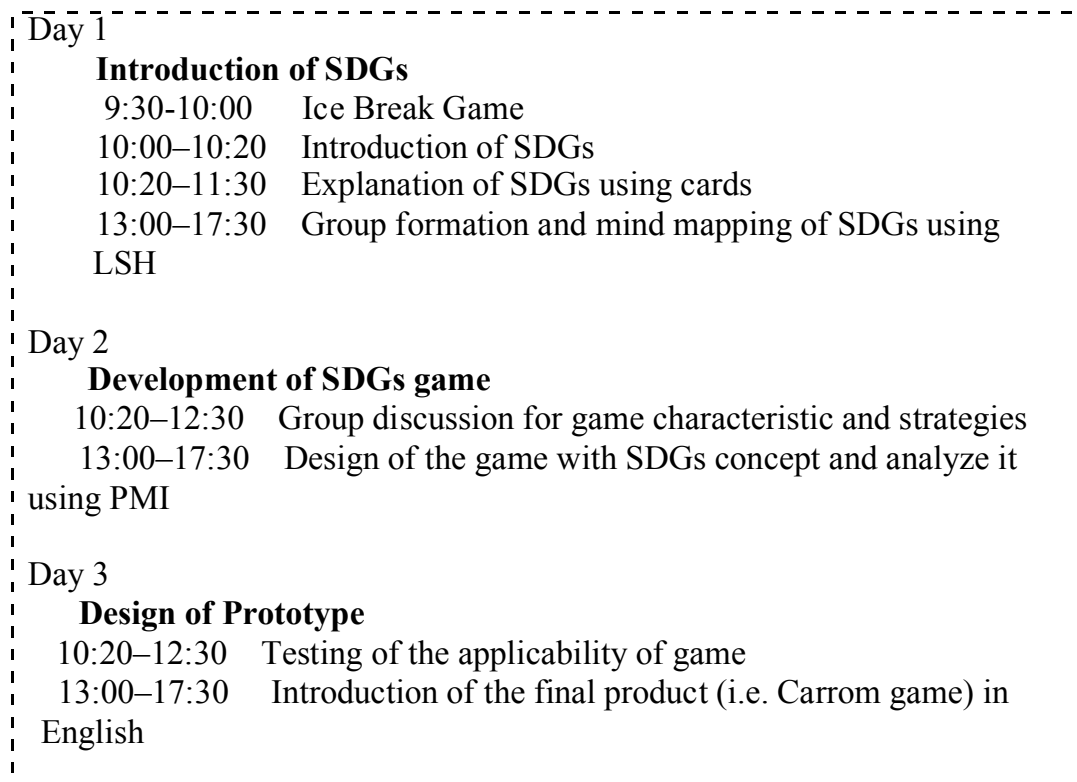

Figure 2. Schedule of the workshop 


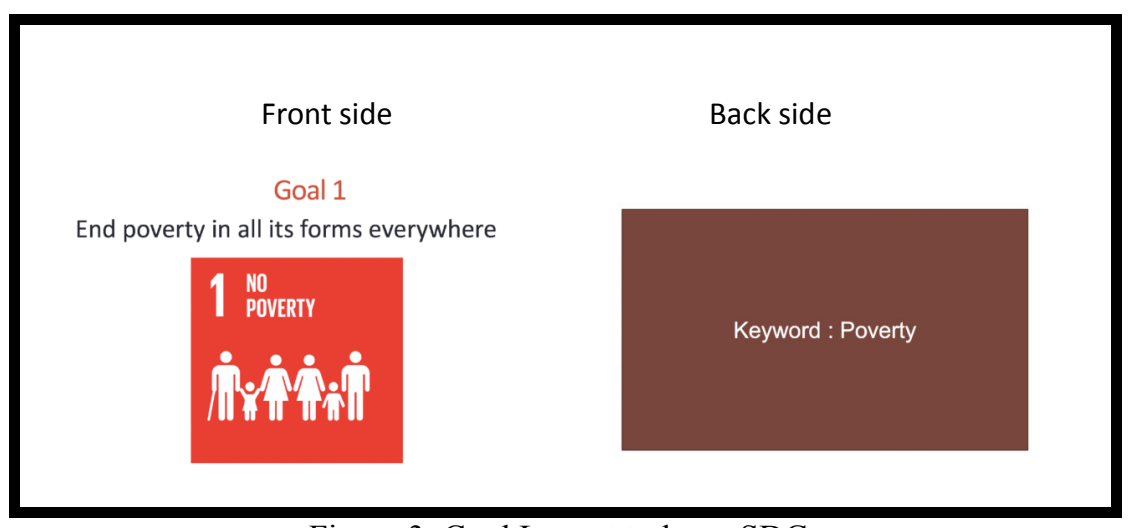

Figure 3. Card Layout to learn SDGs

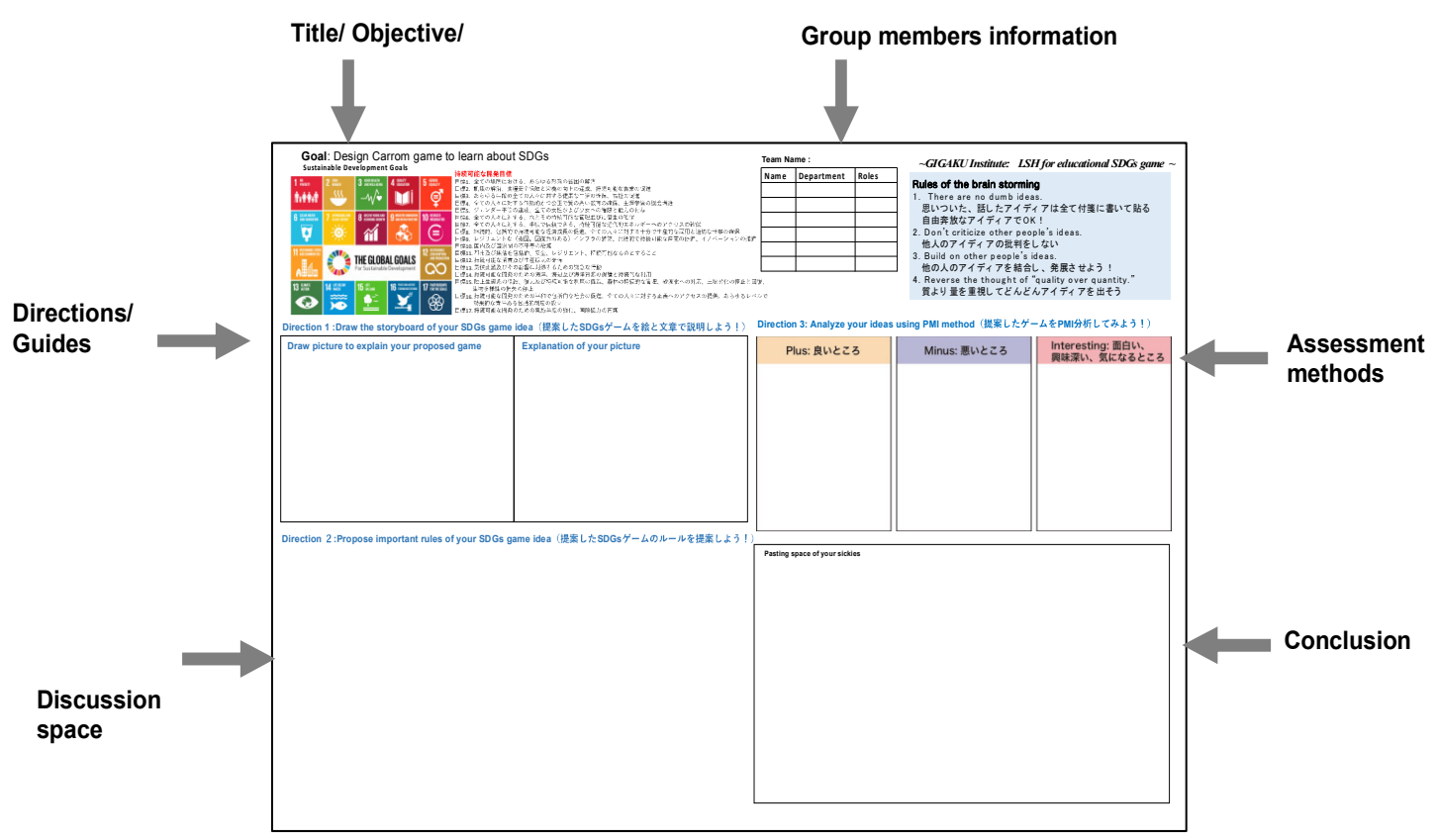

Figure 4. Large sized handout layout used in this study

\subsection{Data collection and analysis}

The data was collected through questionnaires after the workshop. In order to evaluate the improvement of skills in students, two types of questionnaires were used. At the end of each workshop session, all the students were asked to fill the questionnaires. The contents of the questionnaires are summarized in Table 1. i.e. Generic skill questionnaire (A) and Feedback questionnaire (B). The generic skill questionnaire was prepared based on the definition of generic skills and model core curriculum of National Institute of Technology, (National Institute of Technology, 2012). After the completion of the workshop, the feedback questionnaire was collected. The raw data were statistically analyzed by Spearman`s correlation ( $\mathrm{p}<0.001)$ using PAST software (Hammer et al., 2001) and the network analysis graph was constructed using Cytoscape (Shannon et al., 2003).

Table 1. Survey questionnaires

\section{A. Generic Skills Improvement}

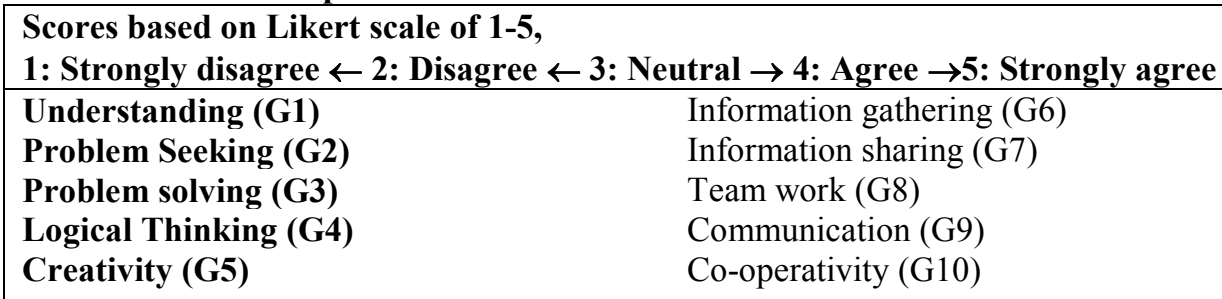




\section{B. Importance of SDGs}

\begin{tabular}{|l|l|}
\hline & $\begin{array}{l}\text { Response scores based on Likert scale } \\
\text { 1: Strongly disagree } \leftarrow \text { 2: Disagree } \leftarrow \text { 3: Neutral } \rightarrow \text { 4: Agree } \rightarrow \text { 5: Strongly agree }\end{array}$ \\
\hline Q1 & $\begin{array}{l}\text { Did you know that SDGs were very important factors for several activities in company, education, } \\
\text { administration, and so on? }\end{array}$ \\
\hline Q2 & $\begin{array}{l}\text { Do you think that introduction of SDGs to your classes and study in your Institute is effective to deeply } \\
\text { understand SDGs? }\end{array}$ \\
\hline Q3 & Do you think that students can have several networks in the world through SDGs as common language? \\
\hline Q4 & Do you want to contribute achieve SDGs by thinking about our future? \\
\hline Q5 & Do you think that Japan has a big role for SDGs achievement in the world? \\
\hline
\end{tabular}

\section{Results and Discussions}

3.1 Generic skill development through group based learning

The main aim of this study was to assess the improvement of generic skills of students based on group based learning. Group based learning is an instructional method in which students work together in small groups toward a common goal. It is also considered as an important characteristic of problem based learning which fosters collaborative learning by stimulating students for deeper interactions ultimately resulting in positive effect on learning (Dolmans et al., 2005). During this group work, the students were given task to design the game for teaching SDGs to the elementary school students.

To examine their skills, ten mostly used skills such as Understanding (G1), Problem seeking (G2), Problem solving (G3), Logical thinking (G4), Creativity (G5), Information gathering (G6), Information sharing (G7), Team work (G8), Communication (G9) and Co-operativity (G10) were chosen. The generic skill assessments were facilitated through questionnaires after the workshops. The skills were quantified by self and group assessment scores. Self evaluation included the individual reflecting upon and evaluating aspects of their own learning and teaching work. While in group evaluation, the individual reflected upon and evaluated the work of others. In this study, likert scale rating was used for determining the development of the generic skills of the students. A rating of 1 (least) to 5 (highest) indicated the level of the skills they developed while working in the group. Students received five rating scales rather than one, enabling them to identify areas of their strength and weakness while working in a group.

The average scores of the group and oneself for each generic skills tested for each day of the workshop is tabulated in Table 2 . The results showed that group based learning was significantly and positively related to all ten generic skills scales. The average group and self scores for most of the generic skills were throughout the workshop than the self scores. The self scores for creativity and information gathering increased from 3.6 to 3.7 and 4.0 to 4.1 respectively. While the other skills showed comparatively decreased scores from day 1 to day 3 . On day 3, all the group scores are above 4 units while the self scores ranged from 3.7 to 4.2 units. The day-wise improvement of generic skills in self ratings did not show significant changes. On the other hand, the day-wise group ratings showed improvement in their skills on day 3 and indicated the highest improvements for understanding $(4.8 \pm 0.5)$, teamwork $(4.8 \pm 0.6)$ and communication $(4.8 \pm 0.4)$ skills.

Table 2. Evaluation of average daily generic skill

\begin{tabular}{|c|c|c|c|c|c|c|c|c|c|c|c|c|c|c|c|c|c|c|c|c|}
\hline \multirow[b]{2}{*}{ Days } & \multicolumn{2}{|c|}{ G1 } & \multicolumn{2}{|c|}{ G2 } & \multicolumn{2}{|c|}{ G3 } & \multicolumn{2}{|c|}{ G4 } & \multicolumn{2}{|c|}{ G5 } & \multicolumn{2}{|c|}{ G6 } & \multicolumn{2}{|c|}{ G7 } & \multicolumn{2}{|c|}{ G8 } & \multicolumn{2}{|c|}{ G9 } & \multicolumn{2}{|c|}{ G10 } \\
\hline & $\mathrm{GA}^{*}$ & $\mathrm{SA}^{* \star}$ & GA & SA & GA & SA & GA & SA & GA & SA & GA & SA & GA & SA & GA & SA & GA & SA & GA & SA \\
\hline 1 & $\begin{array}{l}4.7 \\
(0.4)\end{array}$ & $\begin{array}{l}4.0 \\
(0.5)\end{array}$ & $\begin{array}{l}4.8 \\
(0.4)\end{array}$ & $\begin{array}{l}4.0 \\
(0.5)\end{array}$ & $\begin{array}{l}4.8 \\
(0.4)\end{array}$ & $\begin{array}{c}3.7 \\
(0.7)\end{array}$ & $\begin{array}{c}4.6 \\
(0.4)\end{array}$ & $\begin{array}{l}3.8 \\
(1.0)\end{array}$ & $\begin{array}{c}4.7 \\
(0.4)\end{array}$ & $\begin{array}{l}3.5 \\
(0.9)\end{array}$ & $\begin{array}{c}4.7 \\
(0.4)\end{array}$ & $\begin{array}{c}4.0 \\
(0.5)\end{array}$ & $\begin{array}{c}4.6 \\
(0.4)\end{array}$ & $\begin{array}{l}3.8 \\
(0.8)\end{array}$ & $\begin{array}{c}4.8 \\
(0.3)\end{array}$ & $\begin{array}{l}4.1 \\
(0.6)\end{array}$ & $\begin{array}{c}4.8 \\
(0.4)\end{array}$ & $\begin{array}{c}4.0 \\
(0.5)\end{array}$ & $\begin{array}{c}4.7 \\
(0.4)\end{array}$ & $\begin{array}{l}4.1 \\
(0.6)\end{array}$ \\
\hline 2 & $\begin{array}{c}4.8 \\
(0.5)\end{array}$ & $\begin{array}{c}4.1 \\
(0.6)\end{array}$ & $\begin{array}{c}4.7 \\
(0.6)\end{array}$ & $\begin{array}{l}3.9 \\
(0.6)\end{array}$ & $\begin{array}{l}4.7 \\
(0.6)\end{array}$ & $\begin{array}{l}3.8 \\
(0.7)\end{array}$ & $\begin{array}{l}4.6 \\
(0.6)\end{array}$ & $\begin{array}{l}3.8 \\
(0.7)\end{array}$ & $\begin{array}{c}4.7 \\
(0.6)\end{array}$ & $\begin{array}{l}3.7 \\
(0.8)\end{array}$ & $\begin{array}{c}4.6 \\
(0.7)\end{array}$ & $\begin{array}{c}4.1 \\
(0.7)\end{array}$ & $\begin{array}{c}4.6 \\
(0.6)\end{array}$ & $\begin{array}{l}3.9 \\
(0.9)\end{array}$ & $\begin{array}{l}4.8 \\
(0.6)\end{array}$ & $\begin{array}{l}4.1 \\
(0.9)\end{array}$ & $\begin{array}{c}4.8 \\
(0.4)\end{array}$ & $\begin{array}{l}3.9 \\
(0.3)\end{array}$ & $\begin{array}{l}4.7 \\
(0.4)\end{array}$ & $\begin{array}{c}4.2 \\
(0.6)\end{array}$ \\
\hline 3 & $\begin{array}{c}4.8 \\
(0.5)\end{array}$ & $\begin{array}{c}4.2 \\
(0.4)\end{array}$ & $\begin{array}{c}4.7 \\
(0.5)\end{array}$ & $\begin{array}{l}4.0 \\
(0.5)\end{array}$ & $\begin{array}{l}4.7 \\
(0.5)\end{array}$ & $\begin{array}{c}4.0 \\
(0.4)\end{array}$ & $\begin{array}{l}4.8 \\
(0.5)\end{array}$ & $\begin{array}{l}3.8 \\
(0.9)\end{array}$ & $\begin{array}{c}4.7 \\
(0.5)\end{array}$ & $\begin{array}{c}3.6 \\
(0.8)\end{array}$ & $\begin{array}{l}4.6 \\
(0.5)\end{array}$ & $\begin{array}{l}4.0 \\
(0.5)\end{array}$ & $\begin{array}{l}4.8 \\
(0.5)\end{array}$ & $\begin{array}{c}4.3 \\
(0.5)\end{array}$ & $\begin{array}{c}4.9 \\
(0.4)\end{array}$ & $\begin{array}{l}4.6 \\
(0.5)\end{array}$ & $\begin{array}{c}4.8 \\
(0.4)\end{array}$ & $\begin{array}{c}4.2 \\
(0.6)\end{array}$ & $\begin{array}{l}4.8 \\
(0.6)\end{array}$ & $\begin{array}{l}4.3 \\
(0.5)\end{array}$ \\
\hline
\end{tabular}

*SA: Self-Assessment

**GA: Group Assessment

( ) SD: Standard deviation

Figure 5 illustrates that the overall average scores of the self assessment and group assessment. It is clearly evident that the skills showed good improvement in group assessment rather than self assessment. The self and group evaluation indicated that the students underestimated and evaluated themselves severely and evaluated their group members leniently which could be attributed to their culture. The Japanese culture of modesty did not let themselves assess higher than others (Davies et al., 2002). The other reason would be severity of measuring of 
own skills during presence of the teacher when the students self-assessed their own skills. This might have encouraged them to underestimate, rather than overestimate, the development of skills in them. The results of our study is in agreement with Cheng and Warren (2005) who also observed that students lack confidence in their own ability to review group members. However, this finding urges an important issue for the institutions to further research into the particular sorts of approaches for increasing self confidence in students along with the development of generic skills in them.

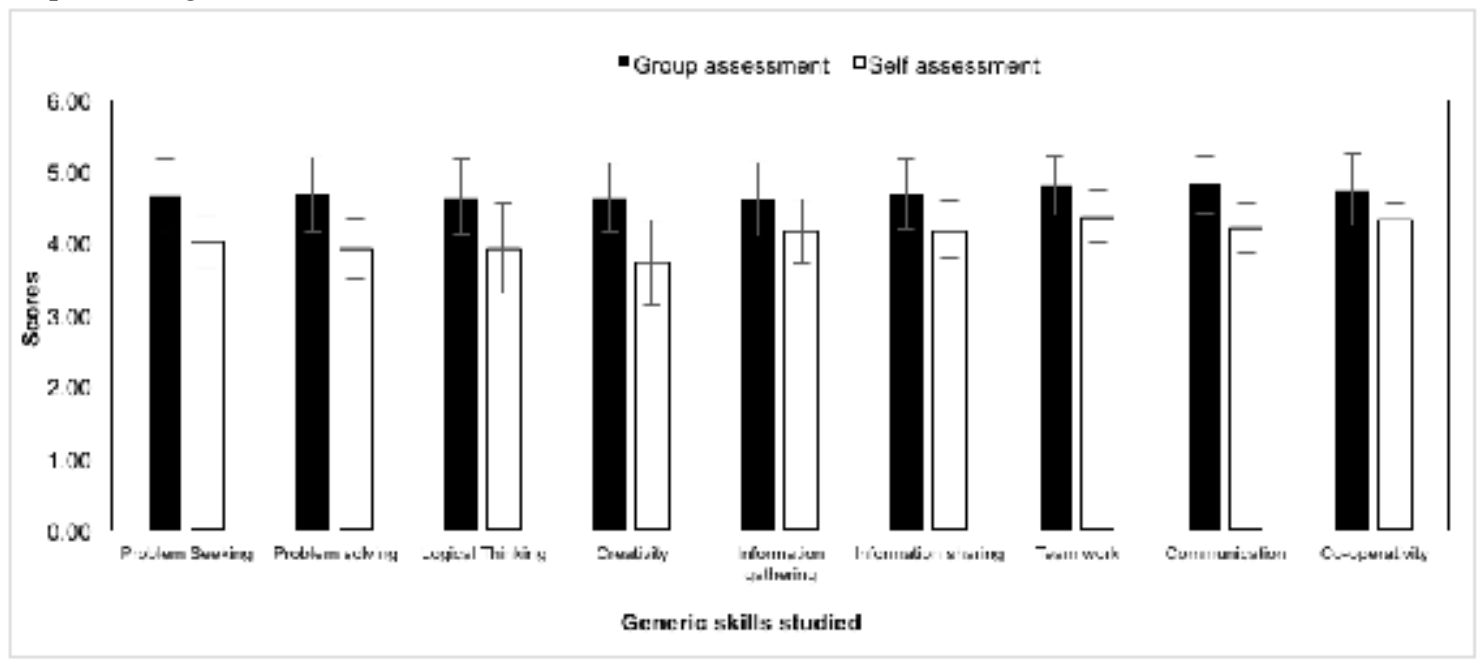

Figure 5. Average values of group and self-assessment of generic skills studied

\subsection{Inter -relationship among generic skills in group based learning}

Generic skills are indispensable attributes in the development of competent scholars (Clanchy \& Ballard, 1995). The development of generic skills is often neglected in university curriculums and university teaching however, it is necessary for employability of alumni (Schaper, Schlömer, \& Paechter, 2012).Such skills are not only applicable to various domains but they also boost the understanding of the interrelation that exists between different aspects (Karst, 2013). Based on Spearman`s correlation, the significant correlation between the generic skills in group assessment data was unbiased. However, the correlation shown by the network analysis of selfassessment data showed remarkable relationship between the skills.

As shown in Figure 6, the communication skill was strongly correlated with information sharing $\left(\mathrm{r}^{2}=0.8109\right.$, $\mathrm{p}<0.001)$ and creativity $\left(\mathrm{r}^{2}=0.7151, \mathrm{p}<0.001\right)$. This kind of activity compels them to share their knowledge, get access to wide range of learning resources and enables one to explore more and come up with creative ideas in a way which is not possible in conventional classroom learning.

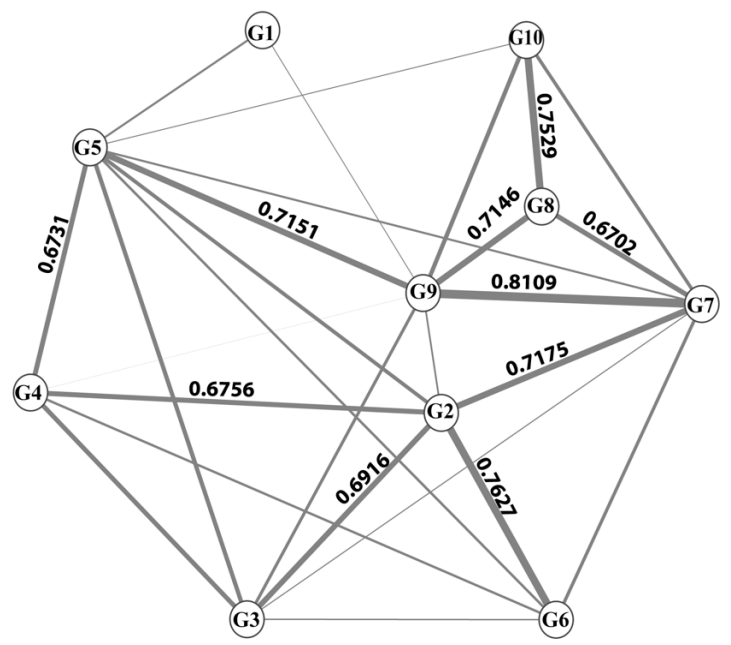

Figure 6. Network analysis showing the correlation among the generic skills according to self assessment

In the group work-based learning activities as a part of the curriculum, the process of information gathering $\left(\mathrm{r}^{2}=0.7627, \mathrm{p}<0.001\right)$ for problem solving $\left(\mathrm{r}^{2}=0.6916, \mathrm{p}<0.001\right)$ becomes equally important as the content and its understanding. Interpersonal skills, planning, time management, meeting the deadlines, resolving conflicts and many other skills were naturally developed when the students were designing the game. Another advantage of group based learning indicated by this study is logical thinking $\left(r^{2}=0.6756, p<0.001\right)$ rather than externally 
regulated as in these activities students actively participate in their own learning. The students were observed to set goals and objectives for learning and follow logical thinking steps to attain their goal. This study revealed that for any group work, a good and balanced team work depended strongly on co-operativity $\left(\mathrm{r}^{2}=0.7529 \mathrm{p}\right.$ $<0.001)$, communication $\left(\mathrm{r}^{2}=0.7146, \mathrm{p}<0.001\right)$ and information sharing $\left(\mathrm{r}^{2}=0.7529 \mathrm{p}<0.001\right)$. Different members of the group worked on different aspects of SDGs goals provided to them with same resources for learning and then they put together what they know individually to accomplish the common goal. The solutions that student bring in these sessions have proven to be very creative and practical. In other words, the simple brain storming by these students can lead to a well thought solution ready to put into action. This method of studying helps institutions to harness students' ideas and gives them a place where creativity has no boundaries and meets up to the high standards required to become a professional engineer specially in a country like Japan, where group work is an essential factor leading towards the growth of an individual as well as the overall organization. The development of good team work and good communication skills among Japanese and international students is a very significant result of this workshop despite the severe self assessment. As, majority of students were reluctant to communicate in English and most of the them were not proficient in English which is similar to the study conducted by Kameyama et al. (2010).

\subsection{Importance of understanding SDGs by young engineering students}

The students were given goal to design game for elementary school. By the end of the workshop, the engineering students used the gained knowledge on SDGs and utilized it to propose carrom game appropriate for the kids to play and learn SDGs. The students were observed converting knowledge into actions and using their potential to develop the solutions for the given goal. The importance of understanding SDGs for engineering students was assessed by using the feedback questionnaire at the end of the workshop. With the vision and consensus set by UN, Japan aims to become a role model and will make efforts worldwide so that no country is left behind (Sustainable Development Knowledge Platform, 2017).When considering the active youth, engineering students in Japan is a competent force and introducing them new concept means catering to the huge mass which will pass on from them. The diversity of technology-related courses as well as other programs offered at the institution serve as one of the most important aspects of creating technologically competent graduates at all levels of the institution ("KOSEN", 2018). The youth have a greater role in pushing different agendas in the goals forward, hence different programs that engage them have to be devised ("The role of youth in sustainable development - perspectives from South Asia", 2018). The core essence of these goals, is, therefore, to give a clear outline of undertakings as well measures for all countries to adopt, and by doing so, contribute to achieve the goals.

The first question addressed student's familiarity with SDGs, where $33 \%$ of the respondents stated that they were aware about SDGs and remaining 67\% never heard about SDGs as shown in Figure 7. The mean of the individuals whose answer was rated as a strong affirmation was 5. Most respondents were sure about their answer hence most of them gave a strong affirmation on their answer (Figure 8). This implies the workshop had a notable contribution to the understanding of SDGs by the students and has a great impact on the prospect of spreading the knowledge of these goals through their networks. There were good interactions among students where they brainstorm to seek the problems in their environment and find the possible solutions using their field of study and express the terms in English. In addition, some descriptions revealed that students had actively tried to think how theories can be executed in their daily life to make their place more sustainable to live. These students understood that studies are theoretical and therefore they actively search for practical applications of theories such as they developed the inter-relation among the different goals and proposed an integrated solution. 


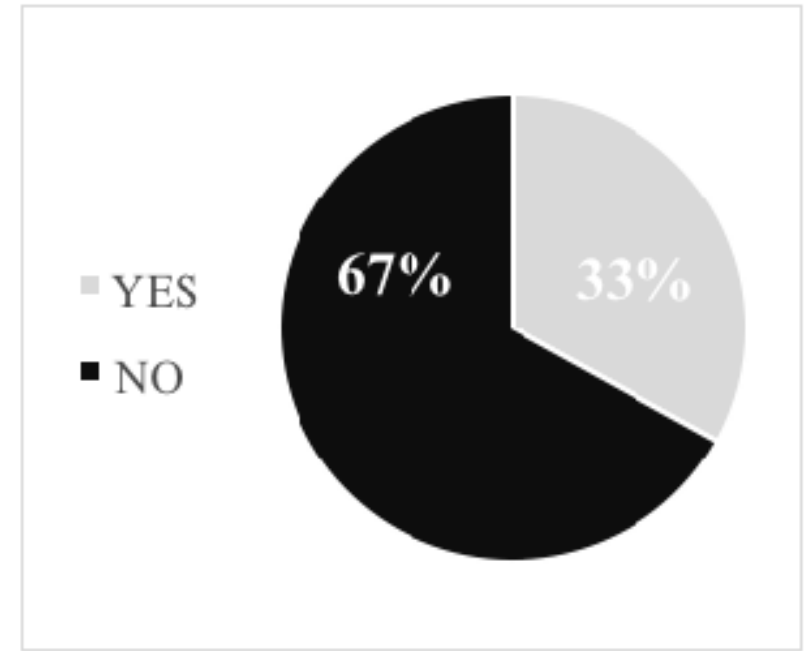

Figure 7 . Responses based on the feedback questionnaire on preliminary knowledge of SDGs

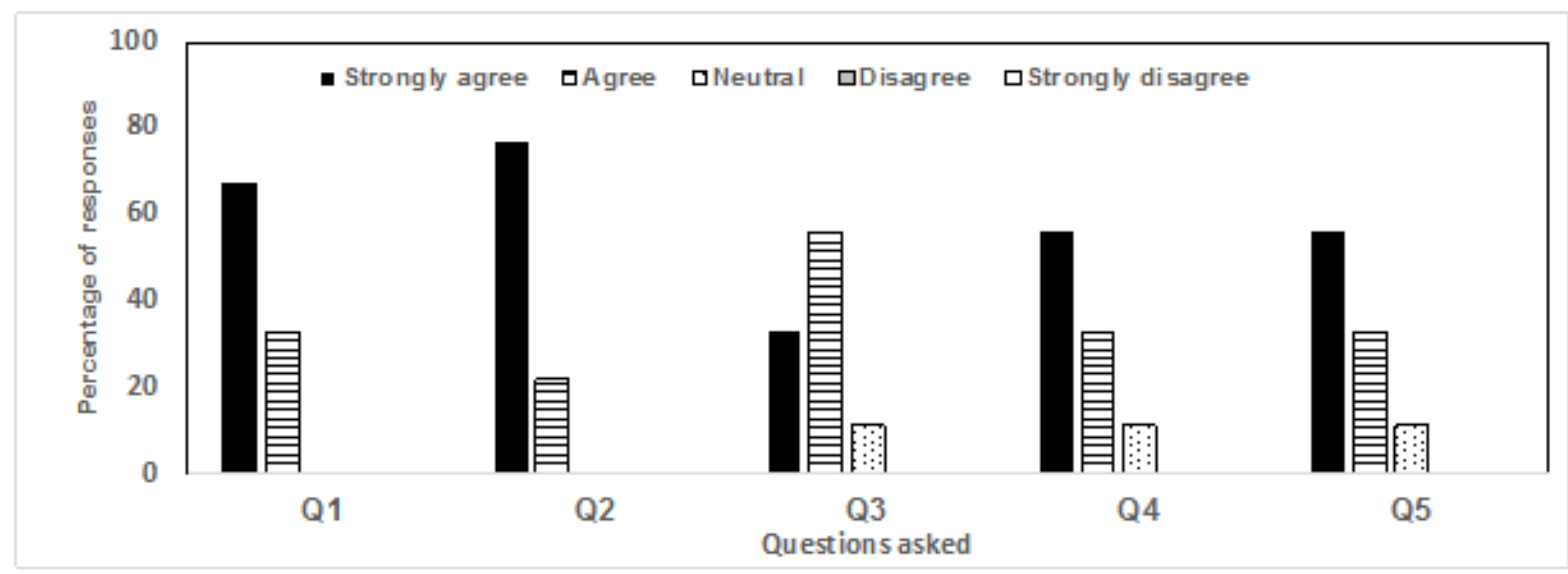

Figure 8. Responses obtained for the preliminary knowledge on SDGs

The prospects of spreading knowledge on SDGs through engineering students is high. This is because technology is one of the core assets that can be used for the achievement of several other objectives. Since they are also technologically competent, they are at a better position to come up with metrics that ensure the achievement of the objectives as well as monitor the progress after putting in place the necessary infrastructure (Lu et al., 2015). Besides, the government, through the ministries of education, Science and Technology, Culture as well as Sports has put in place varied strategies to ensure students learn about SDGs. Given the fact that, engineering institutions are one of the target categories, spreading information on SDGs through students from this institution is likely to be successful (Nomura et al., 2010). When the opportunities are harnessed by engineering students, they are likely to be champions through which the information on the goals are spread.

\subsection{Limitations of this study}

Even though the educational reformations to include generic skills assessment in higher education started decades ago in Japan, its practical implementation is still in infancy. This study tried to address the experiences of generic skills development while working in a group based learning and the results supported that there is positive impact on the students. However, the findings are limited to small student number and the measurement of the knowledge acquisition, therefore more emphasis is needed to develop new techniques and approaches to ensure better understanding of the concepts and its implementation in the day to day life in order to avoid passive learners. Moreover, the students underrated themselves during self assessment while working in a group. Further studies with the greater number of students must be carried out to develop a concrete standardized test for better evaluation and assessments.

\section{Conclusion}

Through research where questionnaires were used as a means of data collection, the development of generic skills through implementation of group based learning was studied. The results showed that group based learning 
has positive impact on the improvement of generic skills. The development of generic skills was reported better in group assessment than self assessment. When the inter-relationship among the skills were assessed, it was found that there is a strong correlation among the generic skills. Our aim was to clarify what general skills were mostly developed related to the experiences of development of their understanding of problems and solutions to attain SDGs. Especially in the light of student learning using group based work environment, results showed that communication, teamwork and understanding skills were closely related to learning and experiences of generic skills development.

Reporting of generic skills through the group and self assessments therefore provided some measures of their comprehension and insights into the skills which needed improvements. However, since relationships were modest, this assessment should be more refined to be considered as a perfect indicator of levels of generic skills attainment. Our findings must therefore be interpreted with caution. Indeed, a more accurate assessment of generic skills development requires the long term observation which could be an important avenue for future research. Furthermore, the educational relevance of this study was explored more by the importance of explicitly evaluating generic skills in the teaching and achieving of SDGs and generating awareness in the youths to take actions for spreading the message of SDGs.

\section{Acknowledgements}

This research was supported by Japan Society for the Promotion of Science KAKENHI Grant Number $16 \mathrm{~K} 12753$.

\section{Disclosure Statement}

No potential conflict of interest was reported by the authors.

\section{References}

Aburatani (2016) Development of Handouts Enhancing Group and Active Learning with Quantitative Assurance Effective Use of Large Sized Handout (LSH), Proceedings of Annual Conference of Japanese society for engineering education, 384-385.

Assessment and Teaching of $21^{\text {st }}$ century skills AT21CS (2010), Status report [Online] Available:https://www.cisco.com/c/dam/en_us/about/citizenship/socioeconomic/docs/ATC21S_Exec_Summary.pdf.

Cheng, W. \& Warren, M. (2005). Peer assessment of language proficiency. Language Testing. 22 (1), 93-121.

Clanchy, J., \& Ballard, B. (1995). Generic skills in the context of higher education. Higher Education Research and Development, 14(2), 155-166.

Cytoscape: a software environment for integrated models of biomolecular interaction networks. Genome research, 13(11), 2498-2504.

Davies, R. J., \& Ikeno, O. (2011). Japanese Mind: Understanding Contemporary Japanese Culture. Tuttle Publishing.

Dolmans, D. H., De Grave, W., Wolfhagen, I. H., \& Van Der Vleuten, C. P. (2005). Problem - based learning: Future challenges for educational practice and research. Medical education, 39(7), 732-741.

Education for Sustainable development goals (UNESCO, 2017) [Online] Available: http://unesdoc.unesco.org/images/0024/002474/247444e.pdf

Glaser, R. (1991). The maturing of the relationship between the science of learning and cognition and educational practice. Learning and instruction, 1(2), 129-144.

Gleason, B. L., Peeters, M. J., Resman-Targoff, B. H., Karr, S., McBane, S., Kelley, K.\& Denetclaw, T. H. (2011). An active-learning strategies primer for achieving ability-based educational outcomes. American journal of pharmaceutical education, 75(9), 186.

Hammer, Ø., Harper, D. A. T., \& Ryan, P. D. (2001). Paleontological statistics software: package for education and data analysis. Palaeontologia Electronica, (4).

Ichitsubo, M., Aburatani, H., Kobayashi, J., Shimono, K.\& Kanestu, T.,(2016). Effective Active Learning (Japanese translation), Group based learning, Chapter 3.

Ito, H. (2017). Rethinking active learning in the context of Japanese higher education. Cogent Education, 4(1), 1298187.

Kameyama, T. (2010). The situation and perspective of English language education at colleges of technology. Journal of Japanese Society for Engineering Education, 58(3), 28-31.

Karst, N. (2013). Generic skills in higher education. Nordic Journal of Information Literacy in Higher Education, $5(1)$.

Kechagias, K. (2011). Teaching and assessing soft skills. MASS Project, September.

KOSEN. (2018). Kosen-k.go.jp. Retrieved 20 February 2018, http://www.kosen-k.go.jp/english/index.html.

Lochman, J. E., Bierman, K. L., Coie, J. D., Dodge, K. A., Greenberg, M. T., McMahon, R. J., \& Pinderhughes, 
E. E. (2010). The difficulty of maintaining positive intervention effects: A look at disruptive behavior, deviant peer relations, and social skills during the middle school years. The Journal of early adolescence, 30(4), 593-62.

Lu, Y., Nakicenovic, N., Visbeck, M., \& Stevance, A. (2015). Five priorities for the UN sustainable development goals. Nature, 520 (7548), 432-433.

National Institute of Technology (2012). Model core curriculum (draft proposal).

Nomura, K., \& Abe, O. (2010). Higher education for sustainable development in Japan: policy and progress. International Journal of Sustainability in Higher Education, 11(2), 120-129.

Sachs, J. D. (2012). From millennium development goals to sustainable development goals. The Lancet, 379(9832), 2206-2211.

Nguyen, D. Q. (1998). The essential skills and attributes of an engineer: A comparative study of academics, industry personnel and engineering students. Global J. of Engng. Educ, 2(1), 65-75.

Schaper, N., \& Horvath, E. (2008). Development and Evaluation of a Model of eTeaching Competence. In $e$ Learning Baltics 2008. Proceedings of the 1st International eLBa Science Conference. Fraunhofer IRB Verlag, Rostock.

Shannon, P., Markiel, A., Ozier, O., Baliga, N. S., Wang, J. T., Ramage, D., \& Ideker, T. (2003). Cytoscape: a software environment for integrated models of biomolecular interaction networks. Genome research, 13(11), 2498-2504.

Stasz, C. (1990). Teaching and Learning Generic Skills for the Workplace. [Online] Available: https://files.eric.ed.gov/fulltext/ED329682.pdf.

Sustainable Development Knowledge Platform (2017). Voluntary National review [Online] Available : https://sustainabledevelopment.un.org/memberstates/japan.

The role of youth in sustainable development perspectives from South Asia. (2018). Southern Voice.[Online]Availablehttp://beta.southernvoice.org/2016/11/23/the-role-of-youth-in-sustainabledevelopment-perspectives-from-south-asia 